\title{
O PODER DO JORNALISMO E O PODER DA IMAGEM A mediatização do VIH-SIDA nos EUA no período 1980-1985
}

Resumo: Aludindo ao poder da imagem, pretendemos demonstrar a forma como o discurso jornalístico e a linguagem imagética relativamente ao VIH SIDA nos EUA, no período de 1980-1985, ajudaram a construir redes de significação estereotipadas a partir de uma agenda noticiosa heteronormativa.

Estas redes de significação, resultantes da mediatização do VIH SIDA pela via acusatória de uma espécie de hedonismo imputado à comunidade gay, traduziram-se entre 1980 e 1985 em processos institucionalizados de discriminação ou indiferença na resolução dos múltiplos problemas associados ao combate à doença, redundando igualmente na desresponsabilização por parte dos atores políticos, e, em especial, por parte da administração de Ronald Reagan.

Palavras-chave: EUA; 1980-1985; mediatização do VIH-SIDA.

\section{THE POWER OF JOURNALISM AND THE POWER OF IMAGE The mediatization of HIV-AIDS in the US from 1980 to 1985}

\begin{abstract}
Alluding to the power of image, we aim to demonstrate how journalistic discourse and visual imagery regarding HIV AIDS in the period from 1980 to 1985 in the USA helped to build stereotyped networks of meaning due to a heteronormative agenda-setting.

These networks of meaning built from the mediatization of HIV AIDS through the accusation of hedonistic practices by the gay community, resulted in institutionalized processes of discrimination as well as a significant indifference in trying to solve the problems linked to the disease, resulting in the lack of accountability on the part of political actors, in particular the administration of Ronald Reagan .
\end{abstract}

Keywords: USA; 1980-1985; mediatization of HIV-AIDS.

\footnotetext{
${ }^{1}$ Bolseiro de Doutoramento da FCT (Fundação de Ciência e Tecnologia) - Centro de Investigação e Estudos de Sociologia do ISCTE - Universidade de Lisboa (Portugal)

Licenciado em Sociologia pela Universidade de Lisboa (tiagoquintanilha@gmail.com)

${ }^{2}$ Bolseiro de Investigação do CIES-IUL /OberCom - Observatório de Comunicação (Portugal)

Mestre em Comunicação, Cultura e TIC pela Universidade de Lisboa (miguel.paisana @ obercom.pt)

${ }^{3}$ Professor Auxiliar Convidado do ISCTE da Universidade de Lisboa (Portugal)

Doutorado em Sociologia pela Universidade de Lisboa (jorge_vieira@iscte-iul.pt)
} 
"You come to room 1013 over at the hospital, Louis, I'll show you America. Terminal, crazy and mean." Angels in America, Belize, Cap. 5, 38, p.50

\section{Introdução}

"The AIDS epidemic has rolled back a big rotting log and revealed all the squirming life underneath it. No American phenomenon has been so compelling since the Vietnam War."

Edmund White

Foram poucas as doenças e os surtos que, no século $\mathrm{XX}$, tiveram um impacto tão avassalador como o vírus VIH SIDA, que se estima tenha surgido na década de 20 do século XX, em Kinshasa, na República Democrática do Congo.

Depois do surto de febre espanhola (1918-1920) (1), que não tem paralelo na história da epidemiologia mundial, o surgimento do VIH SIDA constitui-se como um acontecimento de referência no quadro dos grandes problemas de saúde pública global do século XX, tendo mobilizado cidadãos, investigado-res, técnicos e profissionais de saúde, bem como decisores políticos, com o objetivo de er-radicar uma doença que se alastrava a todos os continentes.

O vírus, identificado pela primeira vez em 1981 (2) pelo CDC (Centers for Disease Control and Prevention, nos EUA), na forma de retrovírus, veio pôr fim à especulação em torno do aumento do número de casos raros de um tipo de cancro designado por Sarcoma de Kaposis e outras formas agressivas de infeção pulmonar - Pneumocystis carinii pneumonia. $O$ mesmo $C D C(\mathbf{3})$, em Setembro de 1982, utiliza pela primeira vez o termo AIDS (Acquired Immune Deficiency Syndrome), descrevendoo da seguinte forma: "a disease at least mode-rately predictive of a defect in cell mediated immunity, occurring in a person with no known case for diminished resistance to that disease" (CDC, Setembro de 1982).

O processo de reconhecimento do vírus VIH SIDA como problema institucionalizado de saúde pública, nos EUA, não foi imediato, tendo sofrido os efeitos de uma sociedade polarizada entre os valores morais da igreja e o pós-revolução sexual nos Estados Unidos da América, num período que coincidiu com o conservadorismo e inépcia da administração Reagan, face ao problema (4).

\section{0 poder do jornalismo na mediatização do VIH SIDA na primeira metade da década de 1980}

O início da década de 1980 foi de histeria coletiva no que diz respeito à discussão da doença, depois de, em 1981, esta ter sido mencionada pela primeira vez numa publicação médica (5).

A primeira metade da década de 1980 marca o início da mediatização (Lundby, 2009; Sumiala, 2014; Silverstone, 2005) do VIH Sida, e, sobretudo, da mediatização da morte associada à nova doença que parecia encontrar na comunidade gay (sobretudo os homossexuais masculinos) a razão do seu surgimento.

Importa referir, antes de mais, que falar de mediatização é falar do papel dos media nas mudanças e transformações nas sociedades modernas e contemporâneas, sendo que os processos de mediatização afetam assim quase todas as áreas da vida cultural e social na pósmodernidade (Lundby, 2009) e moldam as categorias sociais e culturais e as hierarquias associadas às dimensões da vida e da morte. Ao modelar estas categorias sociais e culturais, a mediatização pode implicar uma diferença significativa no resultado e mudança da perceção da morte pública em sociedade (Sumiala, 2014).

Para Strömbäck (2008), o processo de mediatização comporta 4 fases. Uma primeira quando os mass media constituem a fonte informativa mais importante e o principal canal de informação entre cidadãos, instituições políticas e demais atores. Uma segunda fase onde os $m e$ dia se tornam mais independentes de qualquer lógica política. Uma terceira fase em que os meios de comunicação continuam a ser a principal fonte informativa e o principal canal de comunicação entre os diferentes setores da sociedade, mas agindo de uma forma já de tal forma independente, que são os atores sociais a adaptar-se aos media e não o contrário. Uma quarta e última fase em que os atores sociais reconhecem a necessidade de se adaptarem às lógicas mediáticas e à sua noção de noticiabilidade e valor-notícia. 
Um dos primeiros resultados visíveis da mediatização da doença e condição de morte que the estava associada, numa altura de escasso conhecimento científico sobre 0 fenómeno, passou pela classificação da mesma (e subsequente interiorização pela sociedade americana) como sendo o resultado de um hedonismo (Bright, 2012) exacerbado presente na comunidade gay, consequente da sua emancipação sexual nas décadas de 60 e 70. Em última análise, o fenómeno de pânico moral (Cohen, 2011) e diabolização das práticas homossexuais como causadoras da doença acabou mesmo por ser um catalisador de processos reativos de contrarrevolução sexual (Janus, 1993), com repercussão nos fenómenos institucionalizados de desresponsabilização dos atores políticos na figura máxima do $40^{\circ}$ presidente dos EUA, Ronald Reagan, bem como nos episódios de intolerância, discriminação e ostracização dirigidos às comunidades gay nos EUA, na sua forma mais destrutiva, ora acusatória, ou de indiferença no que à resolução do problema dizia respeito. Como refere Bright (2012), a história da SIDA é, em si mesma, uma história de discriminação.

Assim, num primeiro momento, o processo de mediatização do VIH SIDA na primeira metade da década de 1980 desembocou na definição per se do conceito de mediatização, que Roger Silverstone (2015) define como os processos de comunicação que moldam os ambientes social e cultural, assim como as relações entre os seus participantes, a nível indivi-dual e a nível institucional.

Uma das imagens mais proeminentes da administração Reagan ficará marcada pela falta de resposta e atenção dada ao problema que começava a devastar as grandes cidades americanas. Com efeito, a primeira vez que Reagan referiu publicamente a palavra AIDS foi já no ano de 1985, quando mais de 5000 doentes com SIDA haviam morrido das complicações resultantes da doença e quando outras centenas de milhar tinham já contraído a doença (6).

Num documentário realizado por Scott Calonico (7), com o título "When AIDS was funny" (8), faz-se uma pequena incursão à problematização da relação entre a administração de então e o surto da doença, mostrando a forma como a administração lidava com o aparecimento da epidemia. Este cineasta utiliza gravações de três con- ferências de imprensa gravadas em 1982, 1983 e 1984, onde o jornalista conservador Lester Kinsolving, do corpo de imprensa da Casa Branca, colocava questões a Larry Speakes, porta-voz da Casa Branca entre 1981 e 1987, que repetidamente, e quando chamado a analisar o assunto, abordava a questão com comentários homofóbicos e com uma falta de interesse recorrentes.

Um dos veículos legitimadores desta primeira fase de mediatização da doença está relacionado com aquilo a que se designa como "o papel desempenhado pelas convenções inerentes à linguagem jornalística na compreensão da ordem social e na configuração do espaço público" (Correia, 1995, p. 1).

Com efeito, a mensagem jornalística dos inícios da década de 80, relativamente ao fenómeno VIH SIDA nos EUA, era uma mensagem profundamente reificada, que ligava a condição do portador da doença à sua orientação sexual.

Alguns autores (Lichter, 2017) sugerem que o tratamento noticioso, longe de ser objetivo (o que, por si só, encerra discussões controversas), tende a reproduzir e a preservar os interesses hegemónicos das sociedades. Ou, como refere Correia (1995, p. 2), "um elemento que emerge com regularidade é a suspeita de que a linguagem jornalística tende a reproduzir o que é socialmente aceitável ou preditível (...) o jornalismo enfatiza o que é socialmente preditível, correndo o risco de desenvolver uma escrita conforme ao estereótipo".

Por outro lado, "a plena transparência da palavra e do agir é um discurso mítico na medida em que a totalidade ou a plenitude do dizer e do fazer equivaleria à própria negação da linguagem, à morte da palavra ou ao silêncio total" (Rodrigues, 1985, p. 11).

$\mathrm{O}$ primeiro discurso jornalístico relativo ao surgimento do VIH SIDA utilizava então uma linguagem que pretendia introduzir sentido a um fenómeno desconhecido e sem precedentes. Acontece que a sociedade é pura comunicação e toda a comunicação é sociedade (Luhmann, 2000), e o problema da informação e comunicação noticiosas assenta na seletividade do sistema dos mass media e não contém assim qualquer referência à verdade, pois o código binário verdade / falsidade nem sequer lhe é inerente: é antes próprio de um outro siste- 
ma social designado por ciência (Correia, 1995).

Neste sentido, e no início da década de 1980, a imprensa americana, na sequência desta nova doença que surgia associada à comunidade gay, construía a notícia de forma frequentemente pejorativa, no sentido em que gerava desconfiança a partir da representação estereotipada dessa comunidade. Dito de outra forma, a relação com a doença, e o seu tratamento noticioso, eram moldados de acordo com a forma como o homem construía o seu próprio conhecimento da realidade (Luckmann e Berger, 2010).

A realidade de então, entendida como produto da sociedade, era uma realidade profundamente dicotomizada entre os valores libertários e emancipatórios produzidos no pós-revolução sexual e os valores morais de franjas maioritárias da população, cuja palavra de ordem era recolhimento. Recolhimento da vida privada, recolhimento nas relações interpessoais e demonização do hedonismo sexual, sustentados nas clivagens de valores a que McKinnon (1992, p. 13) alude, em parte, na obra "The Politics of Popular Representation: Reagan, Thatcher, $A I D S$, and the movies”, num período em que contrair o vírus ainda era sinónimo de estigmatização.

"O debate em torno da significância do vírus da SIDA permanece intenso. Enquanto a doença for vista como estando associada a "hábitos", escolhendo atingir heroinómanos, homossexuais do género masculino, imigrantes haitianos e crianças filhas de pais toxicodependentes, assim como hemofílicos, os media convencem o público através de um complexo processo de argumentação de que o vírus não terá grandes consequências [para aqueles que não se enquadram num conjunto de práticas determinadas pelo status quo como negativas],

Ao relatarem a doença na forma de construto, os seres humanos, e jornalistas em particular, associavam a doença ao comportamento negligente do seu portador. Criou-se assim o estereótipo do homossexual submetido aos castigos divinos, com todas as implicações nefastas que tal construção das representações sociais acarretou, em especial no efeito de causalidade com as lógicas de desresponsabilização dos atores políticos da administração Reagan, uma administração profundamente conser- vadora, que beneficiou numa primeira fase da linguagem jornalística que atribuía subliminarmente o ónus da culpa à comunidade gay, para assim se demarcar do problema.

Este discurso dominante de desresponsabilização política (no sentido em que gerava indiferença ao nível dos decisores políticos), de ostracização, e profundamente discriminatório, começou a ser lentamente combatido e alterado à medida que o conhecimento sobre a doença também ia sendo maior, com mais investigação e envolvimento da comunidade científica. A linguagem hegemónica referente ao VIH SIDA começou a reinventar-se lentamente, caminhando para um discurso que passava a utilizar o plural majestático e onde cada um começava a interiorizar a ideia de que a infeção pelo vírus não escolhia tons de pele, idades, estratos sociais ou género.

Entrávamos na segunda metade da década de 80 e a resiliência da comunidade gay, que exigia respostas, tornara impraticável a mesma postura de indiferença mantida pela administração Reagan. Em 1987, por exemplo, surge nos EUA um movimento social importante de defesa dos direitos das pessoas com o Síndrome da Imunodeficiência Adquirida, o AIDS Coalition to Unleash Power ou ActUp, que pretendia lutar pelos direitos de todos aqueles infetados pelo vírus. Este movimento, fundado pelo ativista político Larry Kramer, exigia mais legislação, investigação, tratamento e políticas de saúde capazes de mitigar o sofrimento daqueles que sofriam com a doença. Surgiu igualmente como forma de protesto para com movimentos que eram tidos como politicamente irrelevantes na defesa dos direitos dos homossexuais com VIH SIDA, como era o caso do movimento Gay Men's Health Crisis - GMHC. Antes dessa data, em pleno momento de histeria coletiva, vários protestos de rua pediam investigação e o fim da histeria.

No final da primeira metade da década de 1980 ficava clara a transição para uma reflexividade mais abrangente da comunidade norte-americana relativamente às condições definidoras da doença, da sua transmissão e condições de portabilidade. Inaugura-se uma fase de rápidos avanços científicos, não só na vertente da interpretação da doença, como também na vertente das perspetivas terapêuticas (id est AZT), atividade farmacológica associ- 
ada ao combate à doença, etc. Da discussão na esfera pública, a opinião pública e a sociedade civil começam igualmente a pressionar no sentido de exigir respostas por parte dos atores políticos. A própria administração Reagan passou a levar o caso tão a sério que uma brochura informativa sobre o vírus da SIDA foi enviada, em 1987, para todos os 107 milhões de agregados domésticos nos EUA (9).

A morte do ator Rock Hudson, em outubro de 1985, é igualmente considerada um momento de viragem e de desestigmatização, tendo gerado uma forte mediatização que obrigou americanos e americanas a interrogar-se sobre um problema que estava longe de lhes ser distante.

É o fim de uma primeira metade da década caracterizada então, num último momento, por uma linguagem jornalística mais moderada e mais focada em difundir conhecimento, e que inaugura da mesma forma o campo da "comunicação em saúde" (Araújo e Lopes, 2014) na forma que hoje se conhece, e como campo multidisciplinar dentro das ciências da comunicação. Uma linguagem que, em última análise, suportada por um conhecimento mais abrangente da doença, pôde combater mais eficazmente a primeira fase de mediatização da doença, que era profundamente caracterizada pela saturação do comentário em torno da comunidade gay.

Assim, a cobertura e o tratamento noticiosos da doença no fim da primeira metade da década de 1980 compreende já as dimensões de risco e crise, num contexto em que "os jornalistas informam, explicam e enquadram temas de saúde que podem ajudar o cidadão na tomada de decisões sobre a sua própria saúde" (Araújo e Lopes, 2014, p. 51).

No caso do VIH SIDA nos EUA, a comunicação de risco consubstanciou-se na promoção da saúde, no sentido de gerar um entendimento mais alargado, por exemplo, relativamente a condições de disseminação da doença, ao mesmo tempo que pretendia alertar de uma forma mais eficaz para as condições de contágio e 0 alcance das terapêuticas da altura. Como referem Atkin e Wallack (1990), os media são importantes na comunicação dos fatores de risco à população em geral. Por outro lado, o fato de alguns riscos serem novos para o público, leva-os a ser entendidos como pouco naturais e exóticos, condições que potenciam altos níveis de incerteza (Reynolds e Seeger, 2005). Em casos de risco para a saúde pública, a comunicação deve instruir, informar e motivar comportamentos autoprotetores (Vaughan e Tinker, 2009).

Por outro lado, a comunicação de crise passou a estar associada a questões de ordem pública para efetivação do direito fundamental à segurança daqueles que sofriam com a doença. Ações como as campanhas de consciencialização da opinião pública relativamente aos fenómenos de transmissão da doença, pela via da relativização do risco em função das modalidades de proximidade ao portador da doença, começaram a ser no final da primeira metade da década de 1980 uma forma bastante utilizada para reduzir focos de discriminação dirigidos aos doentes infetados com o vírus.

A segunda metade da década de 1980 marca assim um período de consciencialização da opinião pública e de focos importantes de luta, onde os media assumem um papel relevante no sentido em que as notícias de saúde têm um grande impacto na vida das pessoas e que estas passam a contar com os media para lhes explicarem e enquadrarem temas que, de outro modo, lhes seriam desconhecidos (Araújo e Lopes, 2014).

De um processo quase arbitrário de relatar a notícia e o aparecimento do VIH SIDA nos EUA, baseado em conceções simplistas de redes de significação estereotipadas, onde as primeiras estruturas de compreensão precedem o real conhecimento, passámos para uma época de intensa produção e disseminação de conhecimento científico associado à doença, com repercussão na forma como todas as características inerentes ao fenómeno passaram a ser diferentemente relatadas nos media.

\section{0 poder da imagem na mediatização do VIH SIDA nos EUA, na primeira metade da década de 1980}

O jornalismo visual das últimas décadas veio reforçar o poder da imagem no jornalismo, numa nova era que é designada como ocularcêntrica, pictórica e visual (Rose, 2012).

Como refere Mortensen (2017), isto acontece porque a imagem passa a ter a capacidade e a força necessárias à mobilização da opinião pública e de decisão dos proces- 
sos políticos, devido, sobretudo, à dimensão de apelo emotivo e força simbólica que detém.

Refletir sobre a evolução da mediatização do VIH SIDA, sobretudo a partir do poder comunicacional da imagem, implica uma reflexão sobre a conceptualização daquilo que é a imagem, em especial a carga social da fotografia, uma arte com uma origem profundamente científica e com um poder comunicacional de massas inquestionável.

A inquestionabilidade do poder da representação imagética, através da luz enquanto instrumento de forte poder simbólico na definição social e conceptual dos fenómenos, desenvolve-se ao longo do século XX, de forma lenta.

Os pioneiros da reflexão sobre este poder da imagem estática (que depois ganhará um pendor móvel/ dinâmico) foram primeiramente os pensadores do campo da semiótica, iconografia e filosofia. Este facto é fundamental para a compreensão do poder simbólico da imagem impressa, na medida em que a discussão passou a estar focada em torno não do poder social/ comunicacional da imagem, mas sim da sua carga conceptual naquilo que é a evolução da sociedade ao longo do século.

As primeiras notas a reter sobre o desenvolvimento simbólico da fotografia prendem-se com a própria definição de limites entre o aspeto científico e artístico da prática. Prova disto é o facto de a fotografia ter tido usos ambíguos logo desde o início do século, sendo que o seu valor de objetividade não foi logo contemplado ou valorizado.

Um dos campos em que esta objetividade começou desde $\log 0$ a ser questionada foi no campo médico, onde os especialistas demoraram a ganhar consciência do facto de a fotografia poder efetivamente ser mais útil para estudar a anatomia, do que o próprio desenho (Sappol, 2017). Por outro lado, a fotografia demorou a estabelecer-se enquanto elemento fundamental no mundo artístico porque surgia sempre contraposta, em termos de potência representacional, com a pintura, uma arte milenar e com elevado valor social e simbólico. Essa comparação viria a ser determinante na própria definição da arte fotográfica, presa aos cânones da pintura, a insistir fortemente em elementos como a composição e a virtude matemática.
Ao pensar sobre o poder da fotografia enquanto agente de reflexão e apropriação da realidade, Roland Barthes (1980) aborda diretamente esta questão, ao referir que a fotografia não é necessariamente tradução literal do real, mas sim uma construção elaborada e atravessada por um número maior de códigos que extravasam os próprios limites da imagem.

Esta proposta do autor surge em concordância com a teorização de Bourdieu (1981) que situa a prática da fotografia no âmbito mais amplo das práticas sociais de formação de identidade coletiva e descreve a construção de álbuns fotográficos como um ritual de integração que cumpre uma função normalizadora com a mesma clareza de uma lápide tumular. Segundo Paula e Marques (2010), as análises das fotografias no campo artístico seguem usualmente dois caminhos. Um deles é a preocupação com as estruturas internas do trabalho, a natureza dos seus elementos constituintes e as suas interrelações, a procura por padrões de harmonia e tensão, que são interessantes e emocionalmente envolventes. Outro caminho explora questões relacionadas à sua importância filosófica.

A introdução da necessidade de ponderar todos estes elementos na reflexão sobre o poder da imagem fotográfica é desenvolvida por Barthes (1980) com base no pressuposto de que nenhuma fotografia tem um nível de leitura tão bem delimitado como, por exemplo, uma pintura do Renascimento, e se a fotografia, na sua definição elemental, não seguisse outros códigos exteriores à sua existência, a leitura feita por parte do recetor teria de ser encarada como uma leitura universal.

Se a imagem fotográfica comportasse de forma inquestionável essa leitura literal do real, porque é que, por exemplo, no campo dos media e do jornalismo, continua a ter um papel complementar à narrativa, sendo simultaneamente um elemento contextualizado e um elemento contextualizador, e não apenas o segundo? Porque é que não é apresentada isoladamente, mas sim com uma legenda ou com um texto agregado? A resposta parece estar na definição de imagem de Van Leeuwen e Jewitt (2008), que consideram que a imagem é duplamente um relato e um constructo.

A derradeira proposta de Barthes (1980) incide tam- 
bém neste tópico: a fotografia, não sendo ela objetiva, mantém uma relação extremamente próxima com o real.

Contudo, e recuperando características atribuídas à fotografia, como a sua função normalizadora (Paula e Marques, 2010), função de formação da identidade coletiva (Bourdieu, 1981) e de o facto de não ser necessariamente uma tradução literal do real (Barthes, 1980), percebemos que o poder da fotografia e da imagem entronca muitas vezes nos limites da linguagem jornalística e no conceito de mediatização.

Com efeito, e tal como referido no primeiro ponto, também a linguagem jornalística tende a ter uma função normalizadora, no sentido em que tende a reproduzir o que é aceitável, previsível e hegemónico, podendo incorrer no risco de desenvolver uma escrita que potencia o recurso ao estereótipo (Correia, 1995; Lichter, 2017). Por outro lado, a mediatização, modelada pelos dois últimos (poder da fotografia/imagem e da linguagem jornalística) tende a moldar os am-

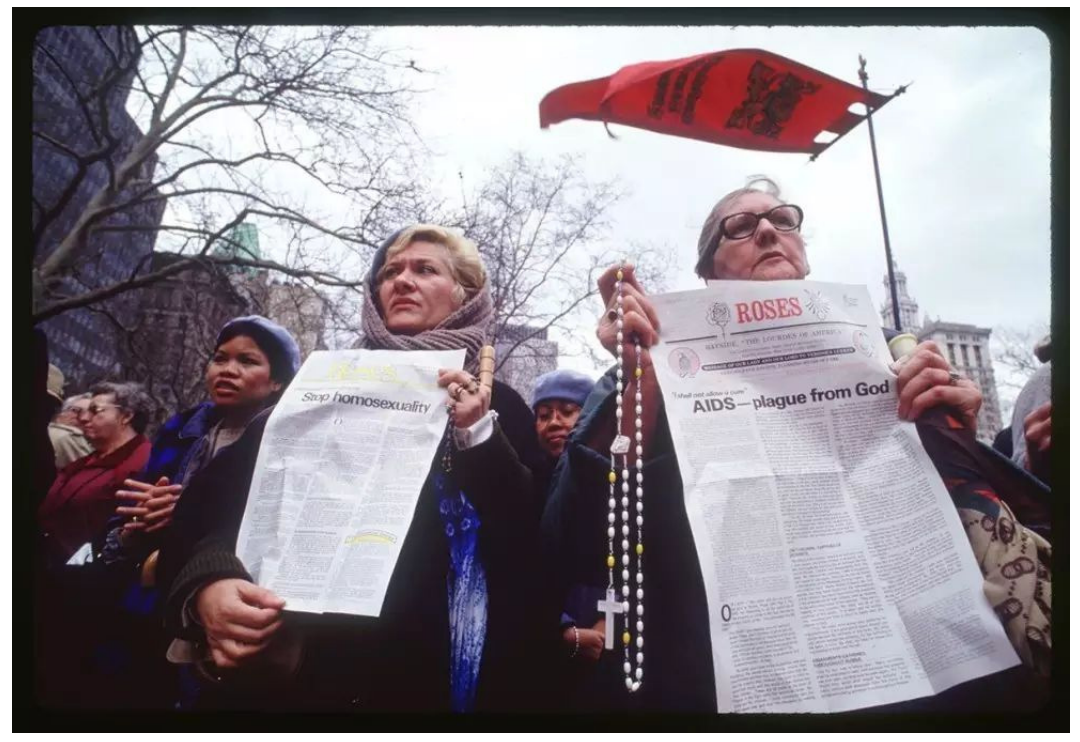

Figura 1 - "AIDS - Plague from God” (Fonte: Bernard Bisson / Getty Images)
Em última análise, determinar o impacto da imagem no fenómeno do VIH SIDA na primeira metade da década de 1980, nos EUA, é uma tarefa que não pode ser dissociada da análise do poder da linguagem jornalística de então, nas redes de significação a partir da representação estereotipada da comunidade gay como o elemento central para a inteligibilidade do fenómeno (Cf. Fig.1). bientes social e cultural, assim como as relações entre os diferentes atores, e as hierarquias associadas às dimensões da vida e da morte nas sociedades pós-modernas (Silverstone, 2005; Lundby, 2009; Sumiala, 2014). O valor abstrato da imagem no processo de representação do real é particularmente sensível no contexto deste tema na medida em que num "conjunto com uma escolha acertada de palavras, as mensagens visuais podem servir para educar, entreter e persuadir, mas, por outro lado, este poder visual também pode ser utilizado para ofender, chocar, enganar, estereotipar e confundir" (Lester, 1995, p. 1). No contexto do pânico em torno do vírus da SIDA, os estereótipos prevalecentes foram perpetuados pelas imagens fornecidas pelos media, não só pela propagação de factos errados face à doença, mas também pelo perpetuar de ideias pré-concebidas de índole mais geral, relativas a género, características físicas e preferências sexuais. 
Por outro lado, não é despiciendo referir que a agenda noticiosa de então, ao erguer-se nas dimensões de histeria coletiva e pânico moral (Cohen, 2011), insistindo na representação da doença nas formas pejorativa e ideológica, redundou naquilo a que McManus (1994), na sua teoria sobre a troca na notícia, designou como o triunfo das notícias com alto valor de entretenimento e baixo valor de orientação, ou a emoção em detrimento da cognição.

Na mesma medida, as imagens escolhidas são a definição daquilo que Amorim, Vitoria e Rossetti-Ferreira (2000, p. 115) identificam como o processo de "organização do meio social, com os sistemas de significações e a estruturação de normas, rituais e regras de conduta (...) um reportório coletivo compartilhado por determinada sociedade ou grupo social (...) dirigindo os comportamentos, sentimentos, conhecimentos e motivações, em certas direções e não noutras". Aquilo que Gruber, Clark, Klempe e Valsiner (2015) designam por "constrangimentos" ou "coações".

No entanto, o papel da mediatização neste processo não serviria apenas para sedimentar uma perceção negativa sobre a doença. Viria a tornar-se, a partir da segunda metade da década de 80 , num instrumento fundamental na desconstrução do medo irracional do VIH SIDA e dos seropositivos. Um exemplo desse facto foi a disseminação massificada de um aperto de mão, sem luvas, da Princesa Diana a um paciente com o vírus da SIDA, um gesto que desafiava quer o conhecimento de que 0 vírus pudesse transmitir-se através do toque, quer as próprias estruturas estereotipadas de perceção face a práticas que estariam associadas à doença (Cf. Fig.2).

A compreensão desta mudança nos processos de mediatização está em grande parte relacionada com as próprias dinâmicas de mudança das estruturas políticosociais na década de 80 .

\section{Considerações finais}

Como referido ao longo do texto, a institucionalização da discriminação da comunidade gay na primeira metade de 1980, legitimada e traduzida nas linguagens jornalística e imagética da altura, encontrou a sua robustez nos processos de mediatização do VIH SIDA e da con- dição de morte que lhe estava associada, bem como na demarcação dos decisores políticos que se refugiavam no escasso conhecimento produzido para se demarcarem de um problema que atingia toda a América.

O fator comum a todos os atores afetados pelo fenómeno foi o desconhecimento generalizado da doença, quer na sua propagação, quer na sua hipotética cura. Os resultados de uma mediatização baseada em processos de desconhecimento e ignorância viria a resultar na criação de sistemas de conceitos pré-concebidos que vão contra o conhecimento científico sobre o vírus e que se cristalizam sob a forma de um medo irracional e pânico moral (Cohen, 2011).

Assim, podemos afirmar que o processo de mediatização do VIH SIDA nos EUA poderá ser dividido em duas fases. Uma, na primeira metade da década de 1980, baseada no pânico moral e na disseminação do desconhecimento, e uma segunda fase, posterior, que é mais consistente com uma nova mediatização do fenómeno com base no conhecimento científico.

Neste seguimento, e reportando-se ao caso sul africano, Tomaselli (2010) fala-nos dos perigos de favorecer soluções infiltradas em discursos enviesados, em detrimento de um discurso de âmbito científico, referindo-se ao discurso do VIH SIDA na África do Sul como sendo um discurso que precisou cedo de ser remediatizado em termos das suas representações, eliminando não só os discursos estereotipados, mas também os raciocínios mistos ou discursos pseudocientíficos.

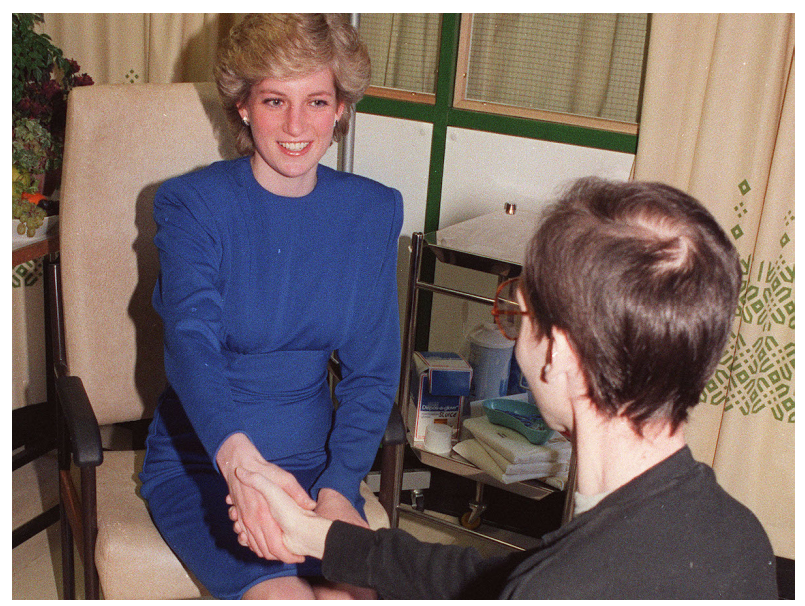

Figura 2 - Aperto de mão, sem luvas, de um paciente Fonte: John Redman/AP. (1987)) 


\section{Notas}

(1) http://ensina.rtp.pt/artigo/gripe-pneumonica-pandemia-1918-1919/

(2) https://www.cdc.gov/mmwr/pdf/wk/mm5021.pdf

(3) https://www.avert.org/professionals/history-hiv-aids/overview

(4) https://www.vox.com/2015/12/1/9828348/ronald-reagan-hiv-aids

(5) http://time.com/3623759/new-england-journal-medicine-aids/

(6) http://www.factlv.org/timeline.htm e https://www.cdc.gov/mmwr/preview/mmwrhtml/00001477.htm

(7) http://www.scottcalonico.com/when-aids-was-funny/

(8) https://www.vanityfair.com/news/2015/11/reagan-administration-response-to-aids-crisis

(9) http://edition.cn.com/2011/HEALTH/05/25/edmund.white.hiv.aids/index.html

\section{Referências bibliográficas}

Amorim, K. de S.; Vitoria, T.; Rossetti-Ferreira, M.C. (2000). Rede de significações. Perspectiva para análise da inserção de bebês na creche Cadernos de Pesquisa, 109, 115-144.

Araújo, R.; Lopes, F. (2004). A mediatização da dengue na imprensa portuguesa: Os casos do Público, Expresso, Jornal de Notícias e Diário de Notícias. OBS*Observatorio, 8(1)1, 49-68.

Atkin, C.; Wallack, L. (Eds.) Amorim, K. de S.; Vitoria, T.; Rossetti-Ferreira, M.C. (2000). Rede de significações. Perspectiva para análise da inserção de bebês na creche Cadernos de Pesquisa, 109, 115-144.

Barthes, R. (2012). A Câmara Clara. Lisboa: Edições 70.

Bourdieu, P.; Castel, R.; Boltanski, L.; Chamboredon, J.-Cl. (1981). Un art moyen. Essay sur les usages sociaux de la photograpie. Paris: Les Éditions de Minuit.

Bright, G.M. (2012). Plague-making and the AIDS epidemic: A story of discrimination. New York: Palgrave Macmillan.

Cohen, S. (2011). Folk Devils and Moral Panics, London: Routledge (1. a ed. 1972).

Correia, J.C. (1995). O poder do jornalismo e a mediatização do espaço público. Covilhã: Universidade da Beira Interior. Disponível em: http://www.bocc.ubi.pt/pag/jcorreia-poder-jornalismo.pdf.

Janus, S.; Janus, C. (1993). The Janus Report on Sexual Behavior. New Jersey: John Wiley \& Sons.

Lichter, S. Robert (2017). Theories of media bias. In K. Kenski and Kathleen Hall Jamieson (2017), The Oxford Handbook of Political Communication. United Kingdom: Oxford Handbooks Online. DOI: 10.1093/oxfordhb/9780199793471.013.44.

Lester, P.M. (1995). Photojournalism ethics timeless issues. In M. Emery and T. Curtis Smythe (Eds.), Readings in mass communication. Dubuque: Brown \& Benchmark Publishers.

Luckmann, N.; Berger, P.L. (2010). A construção social da realidade. DinaLivro.

Luhmann, N. (2000). La realidad de los médios de masas. Barcelona: Anthropos.

Lundby, K. (2009). Mediatization: Concept, changes, consequences. New York: Peter Lang.

McKinnon, K. (1992). The politics of popular representation: Reagan, Thatcher, AIDS, and the movies. Vancouver: Fairleigh Dickinson University Press.

McManus, J. (1994). Market driven journalism. Let the citizens beware? Thousand Oaks: Sage.

Mortensen, M.; Allan, S.; Peters, C. (2017). The iconic image in a digital age. In Photojournalism and Editorial Processes: global similarities, local differences. Nordicom.

Paula, S. de; Marques, K. (2010). A imagem fotográfica como objecto da Sociologia da Arte. Revista de Ciências Sociais, 41(1), $17-26$. 
Reynolds, B.; Seeger, M.W. (2005). Crisis and emergency risk communication as an integrative model. Journal of Health Communication, 10, 43-55.

Rodrigues, A.D. (1985). Figuras das máquinas censurantes modernas. Revista de Comunicação e Linguagens, 1, 9-20

Rose, G. (2012). Visual methodologies: An introduction to researching with visual materials. Los Angeles: Sage.

Sappol, M. (2017). Anatomy's photography: Objectivity, showmanship and the reinvention of the anatomical image 1860-1950 (online essay). Remedia - The history of medicine in dialogue with its present.

Silverstone, R. (2005). “Mediation and Communication”. In C. Calhoun et al. (Eds.) (2005). The International Handbook of Sociology. London: Sage.

Strömbäck, J. (2008). Four phases of mediatization: An analysis of the mediatization of politics. The International Journal of Press/Politics 13(3), 228-246. DOI: 10.1177/1940161208319097.

Sumiala, J. (2014). Mediatization of public death. In K. Lundby (Ed.), Mediatization of communication. Berlin/Boston: Walter de Gruyter GmbH.

Tomaselli, K.G. (2010). Sham reasoning and pseudo-science: Myths and mediatization of HIV /AIDS in South Africa. Communication and Citizenship. IAMCR Braga. Disponível em: http://www.lasics.uminho.pt/ocs/index.php/iamcr/2010portugal/ paper/view/1053

Gruber, C.W.; Clark, M.G.; Klempe, S.H.; Valsiner, J. (Eds.) (2015). Constraints on agency. Explorations of theory in everyday life. New York: Springer.

Van Leeuwen, T.; Jewitt, C. (Eds.) (2008). Handbook of visual analysis. London: Sage.

Vaughan, E.; Tinker, T. (2009). Effective health risk communication about pandemic influenza for vulnerable populations. American Journal of Public Health, 99(S2): S324-S332. DOI: 10.2105/AJPH.2009.162537.

\section{Vídeos}

Calonico, S. (2015). When Aids Was Funny. Documentário. Disponível em: http://www.scottcalonico.com/when-aids-was-funny/ 


\section{ANEXOS}

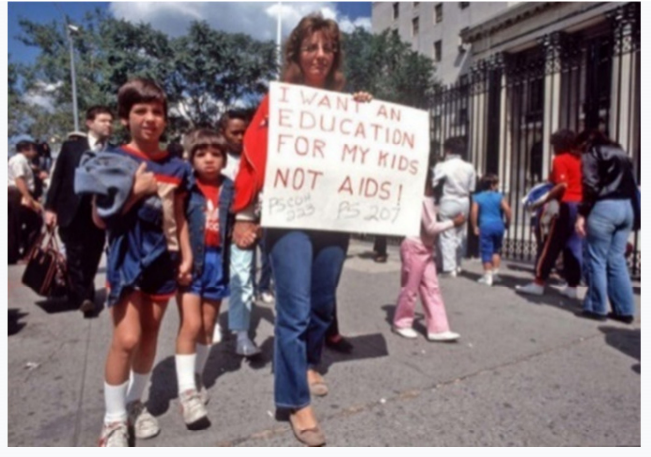

Fig. 3 - "I want an Education for my kids, not AIDS" Fonte: Allan Tannenbaum / Getty Images

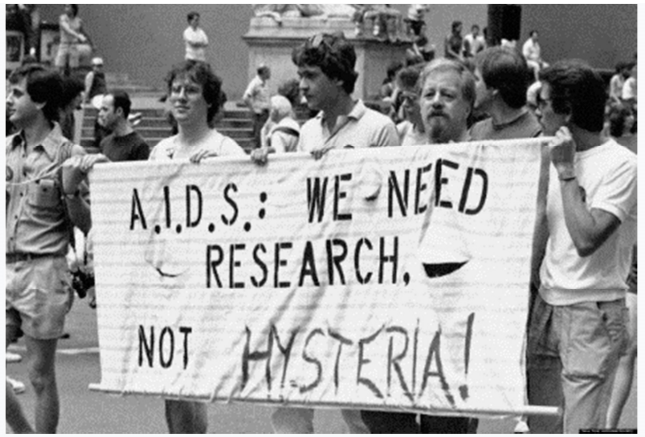

Fig.4 - "AIDS: We need research, not hysteria" Fonte: AIDS research marches down Fifth Avenue, in June 1983

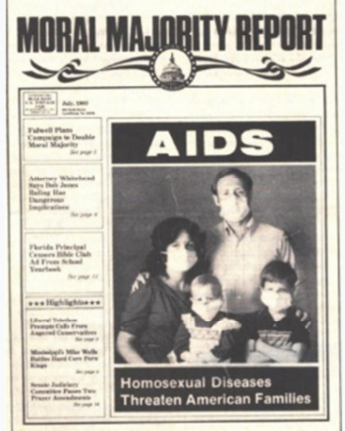

Fig. 7- As doenças dos homessexuais ameaçam as famílias americanas" julho de1983
Fonte: Publicação Moral Majority Report,
Fig. 5 - "GAY AMERICA - Sex,
Politics and The Impact of AIDS" Fonte: Newsweek, 8 de agosto de 1983
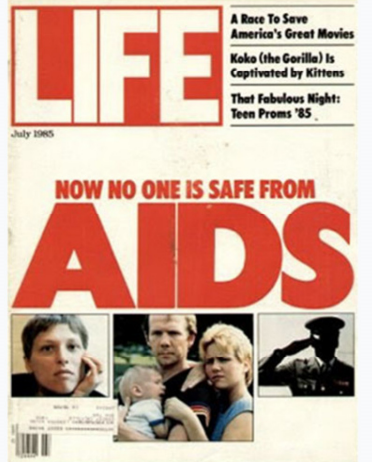

Fig. 6 - "Now no one is safe from AIDS"

Fonte: Revista Life, julho de 1985
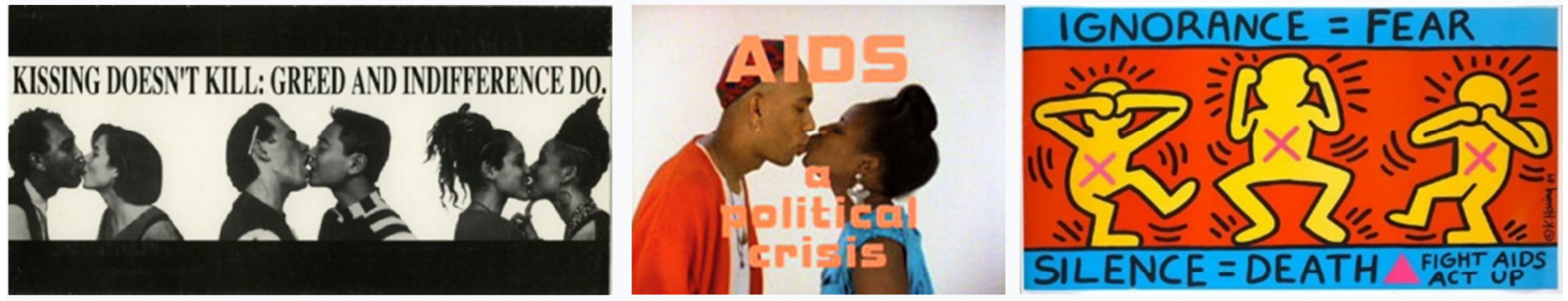

Figs. 8, 9 e 10 -Desmistificando a ignorância

Fonte: Kissing doesn't kill, Gran Fury, 1990 \& Keith Haring for Act Up, 1989 